\title{
THE SELF-DIRECTED LEARNING READINESS SCALE, CONSCIENTIOUSNESS, AND THE PREDICTION OF ENGINEERING STUDENT LEARNING OUTCOMES
}

\author{
Deacon, A.K. ${ }^{1}$, Larson, N. ${ }^{1}$, O’Neill, T.A. ${ }^{1}$ \\ Brennan, R.W. ${ }^{2}$, Eggermont, M. $^{2}$, \&Rosehart, W. ${ }^{2}$ \\ ${ }^{1}$ Department of Psychology, University of Calgary \\ ${ }^{2}$ Schulich School of Engineering, University of Calgary \\ adeacon@ucalgary.ca, nlarson@ucalgary.ca, toneill@ucalgary.ca
}

\section{INTRODUCTION}

Conscientiousness, one of the "Big Five" personality factors, is theoretically and empirically related to academic achievement and encompasses attributes such as Achievement Striving and Selfdiscipline[1][2]. The Self-Directed Learning Readiness Scale (SDLRS), which has been widely validated, is intended to measure a student's learning readiness and attitude toward life-long learning[3]. Life-long learning is an important graduate attribute as stated by the Canadian Engineering Accreditation Board [4] and can be successfully assessed through use of the SDLRS [5]. The purpose of this research is to assess whether Consciousness, SDLRS, or their combination, are able to predict student outcomes in an experiential learning engineering course.

Guglielmino defines a self-directed learner as someone who exhibits persistence in learning, makes plans to facilitate learning, and frames problems as learning opportunities rather than obstacles [3]. Interestingly, the trait definition of Conscientiousness is similar to that of the SDLRS in that it also encompasses attributes of diligence, achievement orientation, and self-discipline [2]. Conscientiousness is one of the strongest personality-related predictors of learning outcomes and academic achievement, a finding which is robust across numerous contexts [1]. Furthermore, the SDLRS is established as a reliable and valid measure of self-directed learning [3], and has been shown to correlate with GPA [6]. Given that Conscientiousness and the SDLRS share some conceptual overlap and are both related to student learning, it is important to determine which of these predictors accounts for the most variance in student outcomes.

\section{METHOD}

The sample consisted of 188 students from the Schulich School of Engineering at the University of Calgary. All students who participated in the study were enrolled in a first year experiential core course titled "Engineering Design and Communication", which uses a sequence of team-based design projects. The data were collected in the middle of the Fall 2013 term though an online survey. The first 100 students to complete the survey received a $\$ 5$ coffee card.

We considered Conscientiousness and Self-Directed Learning Readiness as being predictors of student perceptions of learning, engagement, motivation, and satisfaction with team projects. As noted previously, we chose Conscientiousness as a predictor of student outcomes because it is empirically related to student academic achievement. Additionally, we chose the SDLRS as an additional predictor due its conceptual similarity with the trait of Conscientiousness and because of its theoretical relation to the outcomes of interest (e.g., learning readiness should correlate with motivation and engagement).

Regarding student outcomes, perception of learning was defined as the perceived learning experience associated with the projects [7]. Engagement was defined as the student's involvement with and attachment to the project [8]. Motivation was defined as the student's interest and drive associated with the project [9]. Lastly, satisfaction with the project was defined as the student's attitude towards the project and the work environment [10].

\section{RESULTS}

Multiple regression analyses indicated that the SDLRS clearly outperformed a measure of Conscientiousness in the prediction of student outcomes. More specifically, although both Conscientiousness and SDLRS were significantly related to all four student outcomes, Conscientiousness did not explain additional variance beyond what was accounted for by the SDLRS. These findings support the use of SDLRS in predicting student outcomes as it accounted for significant variance in student perceptions of learning (24\%), project engagement $(25 \%)$, project motivation (18\%), and satisfaction with learning (18\%). In contrast, Contentiousness accounted for minimal variance in the student outcome measures (3- 5\%).

Table 1.Regression for predicting outcomes with Conscientiousness

\begin{tabular}{lcccc}
\hline \multirow{2}{*}{ Outcomes } & \multicolumn{4}{c}{ Conscientiousness } \\
\cline { 2 - 5 } & $b$ & SE $b$ & $\beta$ & $R^{2}$ \\
\hline Learning & $0.31^{*}$ & 0.14 & 0.16 & $.03^{*}$ \\
Engagement & $0.04^{*}$ & 0.14 & 0.19 & $.04^{*}$ \\
Motivation & $0.26^{*}$ & 0.12 & 0.16 & $.03^{*}$ \\
Satisfaction & $0.41^{*}$ & 0.14 & 0.22 & $.05^{*}$ \\
${ }^{*} p<.05,{ }^{* *} p<.001$ & & & &
\end{tabular}

Table 2.Regressions for predicting outcomes with SDLRS scores

\begin{tabular}{lcccc}
\hline \multirow{2}{*}{ Outcomes } & \multicolumn{4}{c}{ SDLRS } \\
\cline { 2 - 5 } & $b$ & $S E b$ & $\beta$ & $R^{2}$ \\
\hline Learning & $1.19^{* *}$ & 0.17 & 0.49 & $.24^{* *}$ \\
Engagement & $1.28^{* *}$ & 0.18 & 0.50 & $.25^{* *}$ \\
Motivation & $0.87^{* *}$ & 0.15 & 0.42 & $.18^{* *}$ \\
Satisfaction & $1.04^{* *}$ & 0.18 & 0.43 & $.18^{* *}$ \\
\hline${ }^{*}<<.05,{ }^{* *} p<.001$ & & & &
\end{tabular}

\section{DISCUSSION}

The research findings presented provide further support for the use of SDLRS in engineering classrooms above and beyond its value for assessing the graduate attribute of "life-long learning". It extends to being a useful tool to be utilized by course instructors to assess and identify those students that may benefit from experiential engineering courses that are designed to enhance not only student readiness for lifelong learning but also engagement levels of students who struggle in this area. Evidence shows students scoring high on the SDLRS are more likely to learn from, be satisfied with, engaged in, and motivated by courses. Consequently, in the future, engineering courses may find it useful to incorporate self-directed learning projects [11] to improve both student outcomes and life-long learning [5] while using the SDLRS prior and post to assess the effectiveness of their efforts.

\section{REFERENCES}

1. S.V.Paunonen and M.C. Ashton, "Big Five predictors of academic achievement", Journal of Research in Personality,35(1), 2001, 78-90

d R.R. McCrae, Revised NEO personality inventory and NEO five-factor inventory professional manual. Odessa, FL: Psychological Assessment Resources, Inc, 1992.

3. L.M. Guglielmino, Development of the Self-Directed Learning Readiness Scale, Doctoral dissertation, University

4. Canadian Engineering Accreditation Board, Accreditation Criteria and Procedures, 2013, Available as of 8 April 2014 from

http://Www.engineerscanada.ca/sites/default/files/W_Accreditation_Criteria_Procedures 2013.pdf 5. R.W. Brennan, M. Eggermont, W. Rosehart, A.K. Deacon, N. Larson, and T.A. O'Neill, "Assessing Life Long Learning in a First Year Design and Communication Course." Proceedings of the $5^{\text {th }}$ Canadia Engineering Education Association Conference, (Canmore, Alberta, 8-11 June), 2014. 6. T.A. Litzinger, J.C. Wise and S.H. Lee, "Self-directed learning readiness among engineering undergraduate 7. P R. Pintrich and EV De Groot, "Motivational , 2005, pp. 215-221. , components of classroom academic performance." Journal of Educational Psychology 82(1), 1990, pp. 33. 8. M.M. Handelsman, et al., "A measure of college student course engagement." Journal of Educational Research, 98(3), 2005, pp. 184

9. D.M. Christophel, et al., "A test-retest analysis of student motivation, teacher immediacy, and perceived sources of motivation and demotivation in college classes." Communication Education 44(4), 1995, pp. 292-306. 10. C.M. Mason and M.A. Griffin, "Identifying group task satisfaction at work." Small Group Research 34(4), 2003,

pp. 413-442.
11. L. Dynan, T. Cate and, K. Rhee, "The impact of learning structure on students' readiness for self-directed learning", Education for Business, pp. 96-100, November-December 2008. 